ARTICLE

https://doi.org/10.1038/s41467-019-10819-4

\title{
Structural defects on converted bismuth oxide nanotubes enable highly active electrocatalysis of carbon dioxide reduction
}

Qiufang Gong ${ }^{1,7}$, Pan Ding ${ }^{1,7}$, Mingquan Xu' 2,7, Xiaorong Zhu ${ }^{3,7}$, Maoyu Wang4,7, Jun Deng ${ }^{1}$, Qing Ma ${ }^{5}, \mathrm{Na} \mathrm{Han}^{1}$, Yong Zhu ${ }^{2}$, Jun Lu (1) ${ }^{6}$, Zhenxing Feng (iD ${ }^{4}$, Yafei Li ${ }^{3}$, Wu Zhou ${ }^{2} \&$ Yanguang $\mathrm{Li}^{1}$

Formic acid (or formate) is suggested to be one of the most economically viable products from electrochemical carbon dioxide reduction. However, its commercial viability hinges on the development of highly active and selective electrocatalysts. Here we report that structural defects have a profound positive impact on the electrocatalytic performance of bismuth. Bismuth oxide double-walled nanotubes with fragmented surface are prepared as a template, and are cathodically converted to defective bismuth nanotubes. This converted electrocatalyst enables carbon dioxide reduction to formate with excellent activity, selectivity and stability. Most significantly, its current density reaches $\sim 288 \mathrm{~mA} \mathrm{~cm}{ }^{-2}$ at $-0.61 \mathrm{~V}$ versus reversible hydrogen electrode within a flow cell reactor under ambient conditions. Using density functional theory calculations, the excellent activity and selectivity are rationalized as the outcome of abundant defective bismuth sites that stabilize the ${ }^{\star} \mathrm{OCHO}$ intermediate. Furthermore, this electrocatalyst is coupled with silicon photocathodes and achieves highperformance photoelectrochemical carbon dioxide reduction.

\footnotetext{
${ }^{1}$ Institute of Functional Nano \& Soft Materials (FUNSOM), Jiangsu Key Laboratory for Carbon-Based Functional Materials and Devices, Soochow University, Suzhou 215123, China. ${ }^{2}$ School of Physical Sciences and CAS Key Laboratory of Vacuum Sciences, University of Chinese Academy of Sciences, Beijing 100049, China. ${ }^{3}$ College of Chemistry and Materials Science, Nanjing Normal University, Nanjing 210023, China. ${ }^{4}$ School of Chemical, Biological, and Environmental Engineering, Oregon State University, Corvallis, OR 97331, USA. ${ }^{5}$ DND-CAT, Synchrotron Research Center, Northwestern University, Evanston, IL 60208, USA. ${ }^{6}$ Chemical Sciences and Engineering Division, Argonne National Laboratory, Lemont IL60439, USA. ${ }^{7}$ These authors contributed equally: Qiufang Gong, Pan Ding, Mingquan Xu, Xiaorong Zhu, Maoyu Wang. Correspondence and requests for materials should be addressed to Z.F. (email: zhenxing.feng@oregonstate.edu) or to Y.L. (email: liyafei@njnu.edu.cn) or to W.Z. (email: wuzhou@ucas.ac.cn) or to Y.L. (email: yanguang@suda.edu.cn)
} 
E lectrochemical $\mathrm{CO}_{2}$ reduction can potentially enable the direct transformation of renewable electricity to valuable chemical feedstocks or fuels, thereby closing the anthropogenic carbon cycle ${ }^{1-5}$. However, its industrial viability is yet to be proven, and essentially contingent upon the development of efficient electrocatalyst materials for $\mathrm{CO}_{2}$ reduction reaction $\left(\mathrm{CO}_{2} \mathrm{RR}\right)^{6-8}$. The challenges come from not only the sluggish reaction kinetics owing to the relative chemical stability of $\mathrm{CO}_{2}$ molecules, but more seriously the limited selectivity caused by the sophisticated $\mathrm{CO}_{2} \mathrm{RR}$ pathways and competing proton reduction process. A multitude of possible $\mathrm{CO}_{2} \mathrm{RR}$ products have been experimentally identified, ranging from $\mathrm{C}_{1}$ products including $\mathrm{CO}$ and formic acid (or formate) to multicarbon $\left(\mathrm{C}_{2+}\right)$ products such as ethylene and ethanol ${ }^{2}$. Even though it is intuitively more desirable to steer the selectivity toward $\mathrm{C}_{2}$ products for their higher industrial values ${ }^{9-12}$, recent technoeconomic analysis shows that the production of CO or formic acid is more economically viable 2,13 . They can be further upgraded chemically or electrochemically.

Formic acid (or formate) is an important product from the two-electron reduction of $\mathrm{CO}_{2}$. It has been widely explored as the hydrogen storage material, and as the chemical fuel for fuel cells; it is also a key chemical intermediate with great industrial significance $^{14,15}$. The global market size of formic acid was 697,000 ton per year in 2013 and is expected to grow to approximately 1 million tons by $2030^{16}$. Carbonylation of methanol is currently the most common strategy for the industrial production of formic acid, which, however, is an energyintensive process. Direct conversion of $\mathrm{CO}_{2}$ to formic acid via the mild and energy-efficient electrochemical approach is highly desired $^{16}$. It is predicted in the "Global Roadmap for Implementing $\mathrm{CO}_{2}$ Utilization" by the Global $\mathrm{CO}_{2}$ Initiative that the global market size of formic acid from $\mathrm{CO}_{2}$ reduction can be up to 475,000 ton year $^{-1}$ by 2030 if suitable electrocatalyst materials are developed ${ }^{16}$. To render the production of formic acid economically compelling, it is suggested that the minimum current density $(j)$ required is $\sim 200 \mathrm{~mA} \mathrm{~cm}^{-2}$, Faradaic efficiency (FE) $>95 \%$ and catalyst durability $>1000 \mathrm{~h}$ under ambient conditions ${ }^{2,13}$. This sets the performance target if we want to bring any electrocatalyst material from benchtop scale science to industrial scale implementation.

Several IIB, IIIA, and IVA metals (i.e., $\mathrm{Pb}, \mathrm{Sn}, \mathrm{Hg}$, In, and $\mathrm{Cd}$ ) have been known for their selectivity toward formic acid or formate since the seminal works by Hori ${ }^{17-19}$. Among these metals, Sn attracts the most attention for its low toxicity and cost. However, Sn-based materials generally suffer from unsatisfactory activity $\left(j<20 \mathrm{~mA} \mathrm{~cm}^{-2}\right)$ and formate selectivity (peak selectivity $<90 \%)^{20-23}$. Very recently, Bi quickly rises as a highly promising candidate for selective formate production. Our own studies as well as others have demonstrated that the selectivity of nanostructured Bi-based materials can reach $\sim 100 \%$ over a broad potential range $\mathrm{e}^{24-28}$. But even with these state-of-the-art electrocatalysts, the measured current density is still an order of magnitude lower than the minimum industrial requirement mentioned above.

In order to narrow or close the huge gap in current density, we need to rationally engineer electrocatalyst materials for not only enlarged surface areas, but also enhanced site-specific activities. In particular, the introduction of structural disorders or defects sometimes can influence the local electronic states and create under-coordinated sites with unexpectedly high activity. Even though the underlying mechanism is sometimes elusive, this strategy has been commonly used for many catalytic and electrocatalytic applications ${ }^{29,30}$. Unfortunately, when it comes to $\mathrm{Bi}$, the direct preparation of its metallic nanostructures with regulated structural defects is very challenging. This is because Bi has a low-melting point so its nanostructures are physically unstable, and $\mathrm{Bi}$ has a high propensity for oxidation upon air exposure so it is also chemically unstable. We reason that an alternative solution is to design defective $\mathrm{Bi}$ compounds (e.g., its oxides) as the template and cathodically convert them to metallic $\mathrm{Bi}$ nanostructures rich in defects for electrocatalytic $\mathrm{CO}_{2} \mathrm{RR}$. The structure of the actual working electrocatalyst thereby can be modulated via tailoring that of the starting template. This strategy is conceptually analogous to the preparation of oxide-derived $\mathrm{Au}, \mathrm{Cu}$ and $\mathrm{Ag}$ nanoparticles reported in literature for high-performance $\mathrm{CO}_{2} \mathrm{RR}^{31-33}$.

Here, we develop a facile solution method to prepare defective $\beta-\mathrm{Bi}_{2} \mathrm{O}_{3}$ double-walled nanotubes (NTs). These oxide nanotubes can be converted to defective $\mathrm{Bi}$ nanotubes under the cathodic polarization as evidenced by operando X-ray absorption spectroscopy (XAS) measurements. When evaluated for electrochemical $\mathrm{CO}_{2}$ reduction, the converted product enables highly active and selective formate production. Our theoretical studies reveal that this excellent activity and selectivity can be attributed to the presence of abundant defective $\mathrm{Bi}$ sites that stabilize the ${ }^{\star} \mathrm{OCHO}$ intermediate.

\section{Results}

Preparation of bismuth oxide NTs. $\mathrm{Bi}_{2} \mathrm{O}_{3}$ NTs were prepared via the controlled hydrolysis of bismuth acetate in ethylene glycol with the presence of poly(vinyl pyrrolidone) (PVP) and a small amount of water (see details in Methods). Key to the synthesis is the introduction of PVP as the structure directing agent. The product is determined to be composed of tetragonal $\beta-\mathrm{Bi}_{2} \mathrm{O}_{3}$ from its X-ray diffraction (XRD) pattern (Fig. 1a). Scanning electron microscopy (SEM) image shows that it consists of onedimensional (1D) nanostructures (Fig.1b). In order to resolve the detailed atomic-scale structure of the product, we carried out simultaneous bright field (BF) and high-angle annular dark field (HAADF) imaging on an aberration-corrected scanning transmission electron microscope (STEM). Interestingly, the 1D nanostructures are revealed to have hollow centers, resembling carbon NTs as evident from the STEM-HAADF image in Fig. 1c. These NTs have a length of 30-60 nm and an inner diameter of $4.5 \pm 0.2 \mathrm{~nm}$. They are demonstrated to be mostly double-walled, with the longitudinal growth along a $\langle 220\rangle$ direction of the tetragonal $\beta-\mathrm{Bi}_{2} \mathrm{O}_{3}$ crystal (Fig. 1d-h). A feature particularly worth noting is that their outer walls are covered with highly defective fragments or clusters. These fragments are presumably resulted from the selective redox etching of NTs by ethylene glycol. Moreover, the crystallographic orientation of $\mathrm{Bi}_{2} \mathrm{O}_{3}$ NTs is confirmed by analyzing the fast Fourier transform pattern of the STEM images (Fig. 1i, j). The main set of spots (in red circles) arise from the crystalline NT projected along the [001] zone axis, while another set of weak spots (in green circles) along the [1-12] zone axis is generated by the small fragments on surface. Electron energy loss spectroscopy analysis of $\mathrm{Bi}_{2} \mathrm{O}_{3}$ NTs shows very weak carbon signal, indicating that there is minute carbon residue on surface (Supplementary Fig. 1). Figure 1k schematically illustrates the structural model of our $\mathrm{Bi}_{2} \mathrm{O}_{3}$ NTs constructed based on the STEM characterization results. Even though the preparation of $\mathrm{Bi}_{2} \mathrm{O}_{3}$ NTs has been sporadically reported ${ }^{34,35}$, our material clearly distinguishes itself from earlier works by its double-walled feature and surface coverage of highly defective fragments. It presents an ideal template for the cathodic conversion to defective metallic Bi nanostructures.

Electrochemical carbon dioxide reduction performance. For electrochemical measurements, the as-prepared $\mathrm{Bi}_{2} \mathrm{O}_{3}$ NTs were loaded onto carbon fiber paper electrode, and tested inside an 

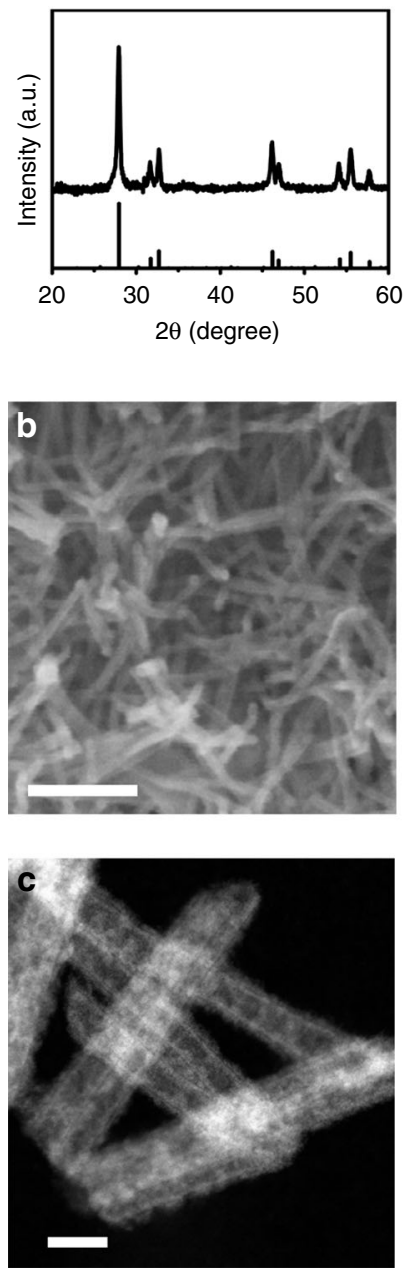
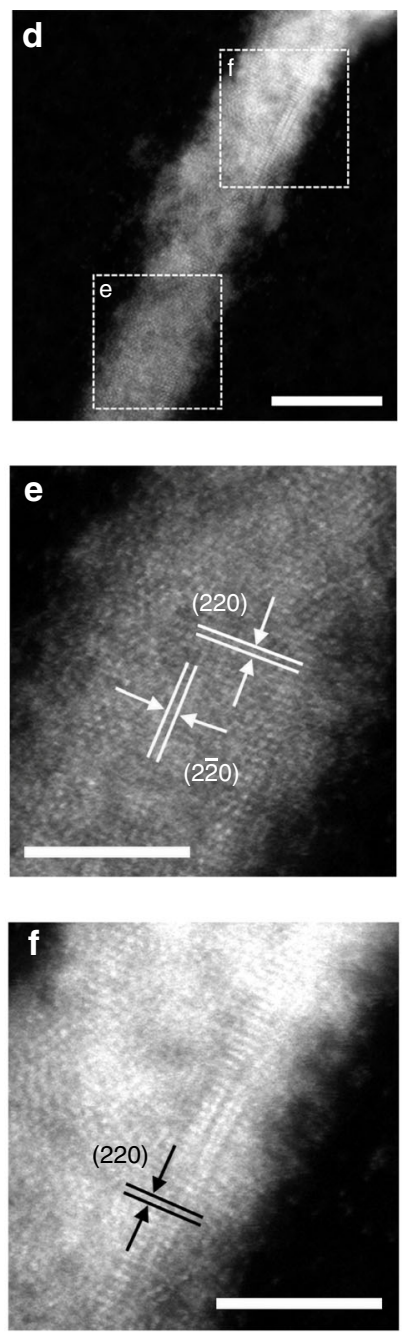
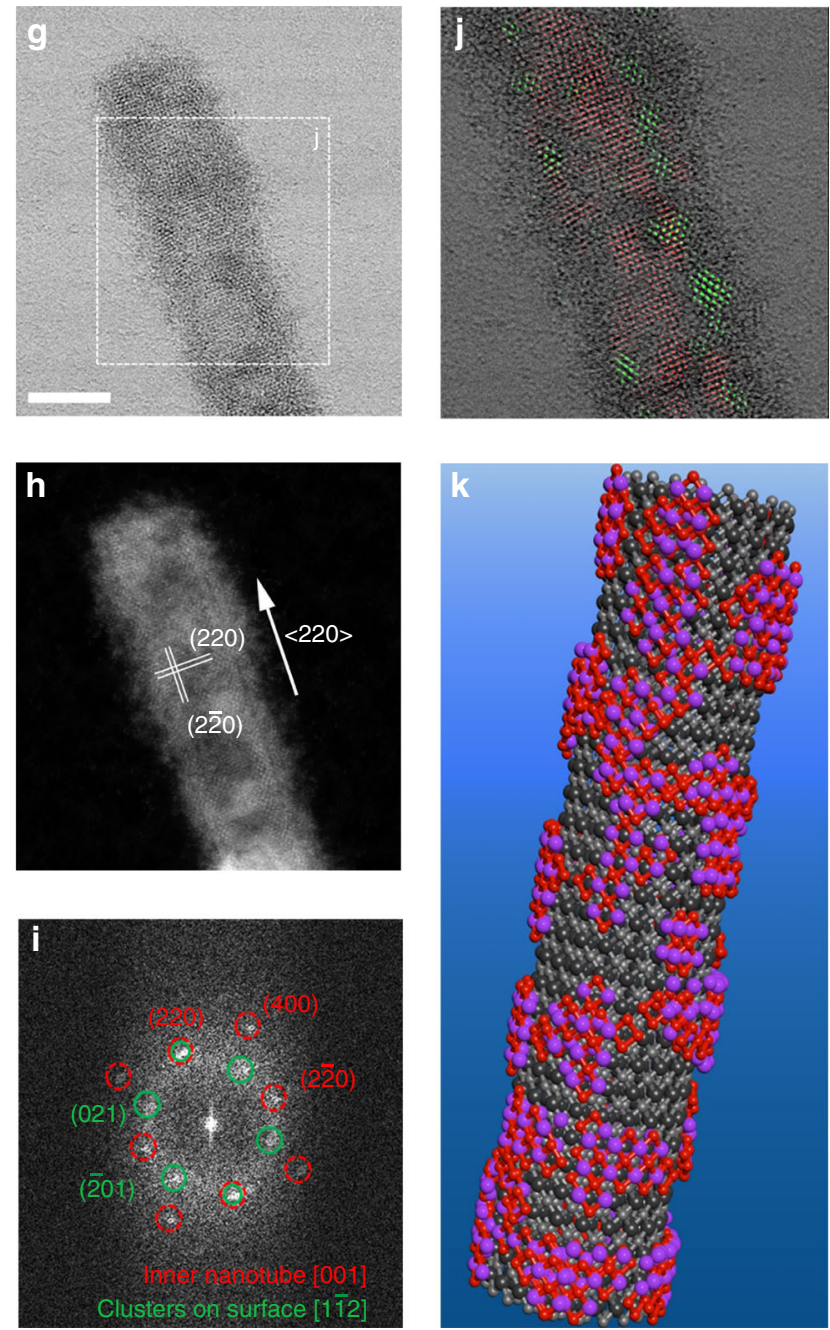

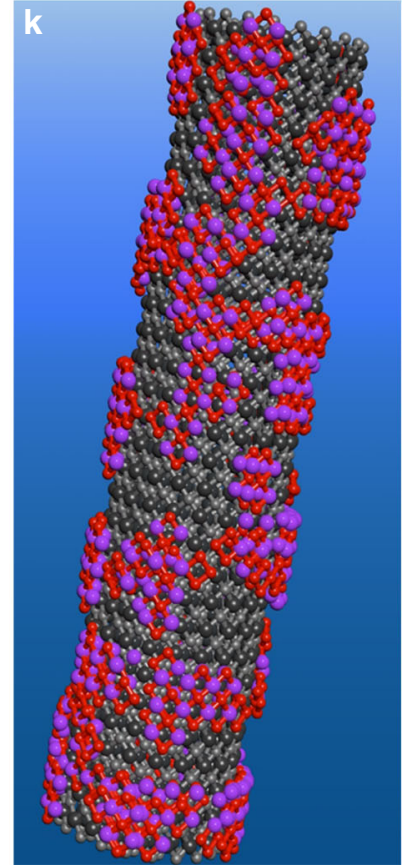

Fig. 1 Structural characterizations of bismuth oxide nanotubes. a XRD pattern, $\mathbf{b} \mathrm{SEM}$ image, and $\mathbf{c}, \mathbf{d} \mathrm{STEM}-\mathrm{HAADF}$ images of $\mathrm{Bi}_{2} \mathrm{O}_{3} \mathrm{NTS}_{\mathrm{A}}$ e, $\mathbf{f} \mathrm{High}-$

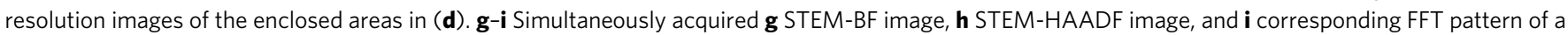
$\mathrm{Bi}_{2} \mathrm{O}_{3}$ nanotube (NT). $\mathbf{j}$ Overlay of the FFT filtered fringes with the original STEM-BF image in ( $\mathbf{g}$ ); the fringes in red are constructed by filtering the FFT spots highlighted in red in (i), and the green fringes are constructed from the green spots. $\mathbf{k}$ Schematic illustration of the structure of $\mathrm{Bi}_{2} \mathrm{O}_{3} \mathrm{NTs}$; the black spheres represent the crystalline inner walls, and the red and purple spheres represent the fragmented outer walls. Scale bar, 100 nm (b); 10 nm (c, d); $5 \mathrm{~nm}(\mathbf{e}-\mathbf{g})$

$\mathrm{H}$-type electrochemical cell filled with $0.5 \mathrm{M} \mathrm{KHCO}_{3}$ using the standard three-electrode configuration (see details in Methods). Upon the initial negative sweep, a pronounced cathodic wave is observed between -0.3 and $0.2 \mathrm{~V}$ (versus reversible hydrogen electrode (RHE), the same hereafter) prior to the reduction of water or $\mathrm{CO}_{2}$ (Supplementary Fig. 2). This cathodic wave is attributed to the electrochemical reduction of $\mathrm{Bi}_{2} \mathrm{O}_{3}$ to metallic $\mathrm{Bi}^{25}$, as supported by the XRD analysis of the reduced electrode showing only the diffraction peaks of rhombohedral Bi (Supplementary Fig. 3a). Remarkably, SEM and low-magnification TEM studies reveal that the 1D tubular morphology with highly fragmented outer surface is largely preserved even after the reduction (Supplementary Fig. 3b-d). Atomic resolution imaging of the reduced material was attempted but unsuccessful since Bi was very sensitive to both oxidation and electron beam irradiation damage. Based on the above characterizations, it can be adequately inferred that metallic $\mathrm{Bi}$ is the active component responsible for any subsequent cathodic reaction, even though the possibility of minor oxygen residues on surface cannot be completely excluded. This working electrocatalyst is named as NT-derived Bi (NTD-Bi) to reflect its history and chemical nature.
Once cathodically converted, NTD-Bi can enable hydrogen evolution reaction (HER) in $\mathrm{N}_{2}$-saturated electrolyte or $\mathrm{CO}_{2} \mathrm{RR}$ in $\mathrm{CO}_{2}-$ saturated electrolyte at less than $-0.3 \mathrm{~V}$. Its $\mathrm{CO}_{2} \mathrm{RR}$ polarization curve abruptly takes off at $\sim-0.6 \mathrm{~V}$, increases sharply and reaches $30 \mathrm{~mA} \mathrm{~cm}^{-2}$ at $-0.8 \mathrm{~V}$ and $64 \mathrm{~mA} \mathrm{~cm}^{-2}$ at $-1.0 \mathrm{~V}$ (Fig. 2a). By contrast, the HER polarization curve evolves more mildly and only delivers $5.6 \mathrm{~mA} \mathrm{~cm}^{-2}$ at $-0.8 \mathrm{~V}$. Such a stark difference immediately evidences that NTD-Bi strongly favors $\mathrm{CO}_{2} \mathrm{RR}$ over HER. To quantitatively determine the $\mathrm{CO}_{2}$ reduction products, NTD-Bi was biased at several selected potentials between $-0.28 \mathrm{~V}$ and $-1.05 \mathrm{~V}$ (Fig. 2b). In agreement with previous studies ${ }^{25-28}$, formate is found to be the predominant product from $\mathrm{CO}_{2}$ reduction. It is first reliably detected at as early as $-0.38 \mathrm{~V}$. The initial $\mathrm{FE}$ is calculated to be $4.4 \%$, which then rapidly rises to $93 \%$ at $-0.7 \mathrm{~V}$, and maintains $>93 \%$ between approximately -1.0 and $-0.7 \mathrm{~V}$ (Fig. 2c). In addition to formate, minor amounts $(<3 \%)$ of $\mathrm{CO}$ and $\mathrm{H}_{2}$ are also measured. Furthermore, the formate partial current density is derived. It attains an unprecedented value of $60 \mathrm{~mA} \mathrm{~cm}^{-2}$ at $-1.05 \mathrm{~V}$ (Fig. 2d). As far as we are aware, the combination of great formate selectivity over a broad potential window and great current 

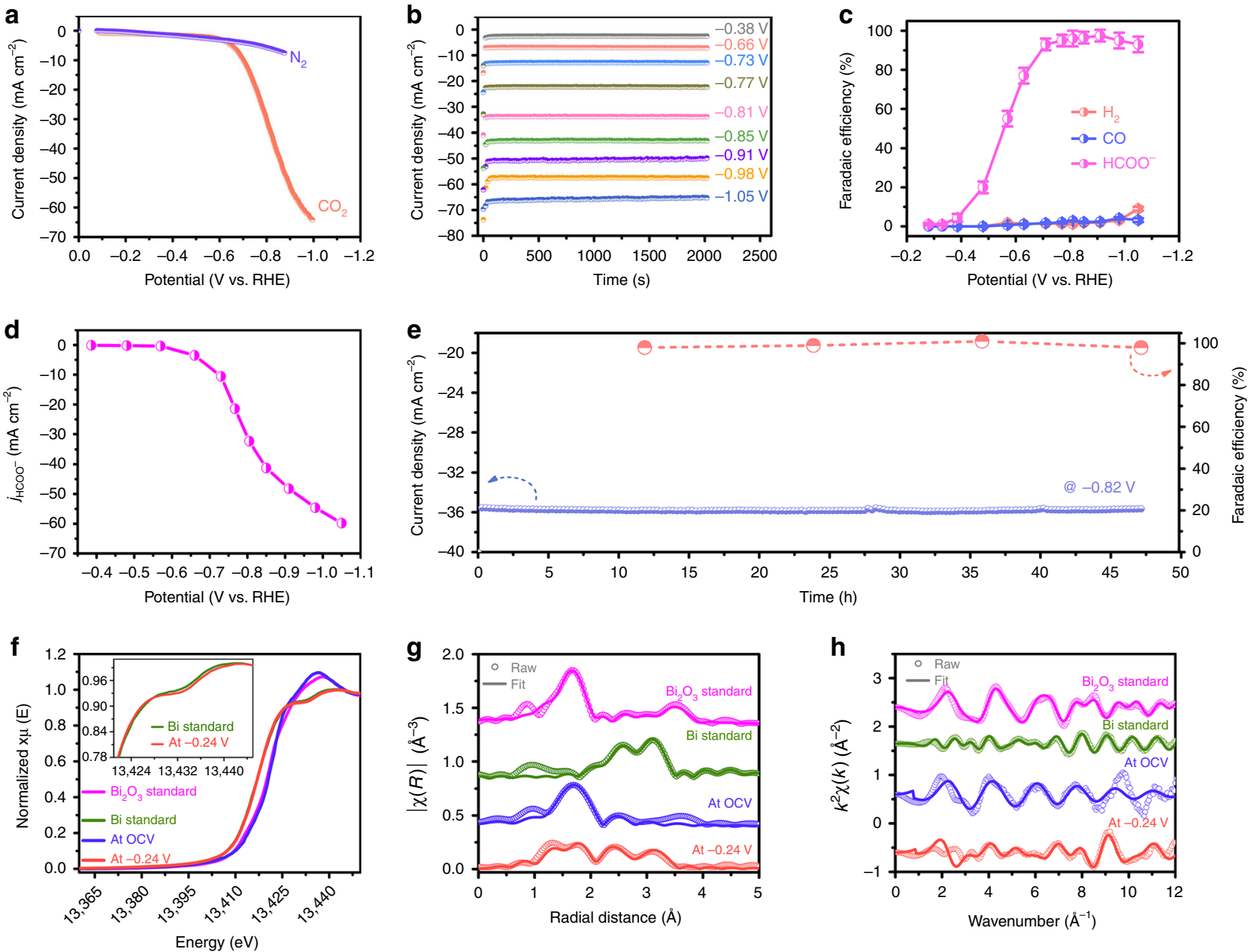

Fig. 2 Electrochemical carbon dioxide reduction measurements in the $\mathrm{H}$-type cell. a Polarization curves of nanotube-derived $\mathrm{Bi}\left(\mathrm{NTD}-\mathrm{Bi}\right.$ ) in $\mathrm{CO}_{2}$ or $\mathrm{N}_{2}-$ saturated electrolytes. b Chronoamperometric responses in $\mathrm{CO}_{2}$-saturated electrolyte at different potentials as indicated. $\mathbf{c}$ Potential-dependent Faradaic efficiencies of $\mathrm{HCOO}^{-}, \mathrm{CO}$, and $\mathrm{H}_{2}$. d Formate partial current density derived from (b) and (c). e Long-term amperometric stability and corresponding selectivity change at $-0.82 \mathrm{~V}$. $\mathbf{f}$ Operando $\mathrm{Bi}$ L-edge XANES spectra of $\mathrm{Bi}_{2} \mathrm{O}_{3}$ nanotubes (NTs) at OCV and NTD-Bi at $-0.24 \mathrm{~V}$ in comparison with $\mathrm{Bi}$ or $\mathrm{Bi}_{2} \mathrm{O}_{3}$ standards; inset plot is the partially enlarged spectra. $\mathbf{g}$, $\mathbf{h}$ Fitting results of the operando EXAFS spectra to ( $\mathbf{g}$ ) $\mathrm{R}$ space and (h) $\mathrm{K}$ space

density is far superior to any other known formate-producing $\mathrm{CO}_{2} \mathrm{RR}$ electrocatalysts (including $\mathrm{Sn}$, In, and N-doped carbon), whose peak formate selectivity $(<90 \%)$ and peak current density $\left(<20 \mathrm{~mA} \mathrm{~cm}^{-2}\right)$ are generally limited and attained only at high overpotentials $(\eta>0.8 \mathrm{~V})^{36-44}$. It is also considerably improved over all previous Bi-based materials ${ }^{25-28}$, in particular on the current density, thereby unambiguously underlining the unique advantage of our NTD-Bi with abundant structural defects.

In addition to its excellent activity and selectivity, NTD-Bi also exhibits satisfactory long-term durability. Bulk electrolysis was performed at $-0.82 \mathrm{~V}$ for $48 \mathrm{~h}$. The total current density of NTDBi stabilizes at $\sim 36 \mathrm{~mA} \mathrm{~cm}^{-2}$ during the course of evaluation (Fig. 2e). Its formate FE was periodically determined by extracting a small volume of electrolyte without interrupting the electrolysis every $12 \mathrm{~h}$. The value is found to be highly consistent and within the range of $\sim 98-100 \%$.

Operando XAS measurements. In order to probe the oxidization state and local structure of $\mathrm{Bi}$ during $\mathrm{CO}_{2} \mathrm{RR}$, we carried out operando XAS measurements at the Bi L-edge (see details in Methods). During the measurements, the working electrode was biased at a few selected potentials from the open circuit voltage $(\mathrm{OCV})$ down to $-0.78 \mathrm{~V}$. Each potential was held for at least
20 min prior to XAS measurements to ensure that the steady state was reached, and was further kept for at least $1 \mathrm{~h}$ for data collection. As shown in Fig. $2 \mathrm{f}$, the Bi edge of the X-ray absorption near edge structure (XANES) at the OCV condition aligns well with that of the $\mathrm{Bi}_{2} \mathrm{O}_{3}$ reference. When the potential is decreased to $-0.24 \mathrm{~V}$, the characteristic of $\mathrm{Bi}(\mathrm{III})$ edge at $13.423 \mathrm{keV}$ gradually shifts to a lower energy of $13.417 \mathrm{keV}$ that aligns with the XANES edge of $\mathrm{Bi}$ metal foil. Further reduction of the working potential results in no additional shift of the XANES edge. Their corresponding XANES spectra are omitted from Fig. $2 \mathrm{f}$ for the sake of clarity. Above observation confirms that $\mathrm{Bi}_{2} \mathrm{O}_{3}$ NTs are reduced to metallic $\mathrm{Bi}$ prior to $\mathrm{CO}_{2} \mathrm{RR}$.

Furthermore, we conducted model-based analysis to quantify the operando extended X-ray absorption fine structure (EXAFS) results. The models were a combination of scattering paths from $\mathrm{Bi}_{2} \mathrm{O}_{3}, \mathrm{Bi}$ metal, and the theoretically calculated $\mathrm{Bi}$ metal with different absorbed ligands (e.g., ${ }^{\star} \mathrm{OCHO}$ ) on surface. The data and fitted spectra are shown in Fig. $2 \mathrm{~g}, \mathrm{~h}$ and the fitting parameters are listed in Supplementary Table 1 . It is noted that the $\mathrm{Bi}-\mathrm{O}$ coordination number $(\mathrm{CN})$ of $\mathrm{Bi}_{2} \mathrm{O}_{3}$ NTs at OCV is calculated to be $3.5 \pm 0.6$, which is markedly smaller compared with the expected value for the bulk material $(\mathrm{CN}=5)$. This under-coordination can be rationalized by its highly defective 
nature, in good agreement with our STEM characterization results of $\mathrm{Bi}_{2} \mathrm{O}_{3}$ NTs. At $-0.24 \mathrm{~V}$ and beyond, $\mathrm{Bi}_{2} \mathrm{O}_{3}$ NTs are reduced to NTD-Bi. The presence of the $\mathrm{Bi}-\mathrm{O}$ scattering paths from our EXAFS fitting can be reasonably assigned to chemisorbed ${ }^{\star} \mathrm{OH}$ and ${ }^{\star} \mathrm{OCHO}$ (intermediate to formate) species (Fig. 2g). This is similar to previous observations on the chemisorbed intermediates such as ${ }^{\star} \mathrm{OH}$ and ${ }^{\star} \mathrm{H}$ on Pt surface during electrochemical oxygen reactions ${ }^{45,46}$. Note that the XANES spectrum of NTD-Bi at $-0.24 \mathrm{~V}$ deviates slightly from that of the Bi metal at the energy around $13435 \mathrm{eV}$ (the inset of Fig. 2f), which is also similar to the change in Pt L-edge XANES when ${ }^{\star} \mathrm{OH}$ and ${ }^{\star} \mathrm{H}$ are chemisorbed on $\mathrm{Pt}$ metal surface ${ }^{45-47}$. More importantly, the $\mathrm{CN}$ of $\mathrm{Bi}-\mathrm{Bi}$ is determined to be $2.6 \pm 1.8$ at $-0.24 \mathrm{~V}$, significantly smaller than that of Bi metal foil $(\mathrm{CN}=6)$, indicating the existence of many low-coordination sites in NTD$\mathrm{Bi}$. Even though we are unable to pinpoint the exact atomic configurations of these low-coordination sites, our EXAFS results here provide solid evidence to the presence of abundant defects or vacancies in our material under the actual working condition.

Flow cell assessments. To demonstrate the commercial viability of any formate-producing $\mathrm{CO}_{2} \mathrm{RR}$ electrocatalyst, the minimum current density required is estimated to be $\sim 200 \mathrm{~mA} \mathrm{~cm}^{-2}$. Such a large current density is difficult to attain using conventional working electrode and electrochemical cell setup since $\mathrm{CO}_{2}$ has limited solubility in aqueous electrolyte ${ }^{10}$. To this end, we deposited NTD-Bi on a gas diffusion layer (GDL) and assessed its performance using a flow cell reactor (Fig. 3a and Supplementary Fig. 4) (see details in Methods). Within this cell configuration, $\mathrm{CO}_{2}$ can be directly supplied to the cathode, quickly diffuse to and react at the solid-liquid-gas triple phase boundaries, thereby lifting the limitation on its electrolyte solubility ${ }^{10,48}$. A peristaltic pump was used in our experiment to force the catholyte circulation so as to dilute the formate accumulation and buffer the electrolyte $\mathrm{pH}$ change.
We first tested the flow cell with $1 \mathrm{M} \mathrm{KHCO}_{3}$. The $\mathrm{CO}_{2} \mathrm{RR}$ polarization curve of NTD-Bi is observed to have an onset potential at $\sim-0.6 \mathrm{~V}$ (Fig. $3 \mathrm{~b}$ ), which is similar to the value measured from the standard H-type cell. The advantage of using flow cells over conventional cells is clearly manifested by the significantly larger current density. For instance, the former delivers $136 \mathrm{~mA} \mathrm{~cm}^{-2}$ at $-0.86 \mathrm{~V}$, while the latter delivers $44 \mathrm{~mA}$ $\mathrm{cm}^{-2}$ under the same potential. This more than twofold gain in the current density results from the rapid $\mathrm{CO}_{2}$ diffusion through GDL. FE analysis unveils that the average selectivity for formate is $99 \%$ at $-0.78 \mathrm{~V}$ and $97 \%$ at $-0.83 \mathrm{~V}$ (Fig. 3c), and hence supports that the large cathodic current density is mostly contributed by $\mathrm{CO}_{2}$ reduction to formate.

Another advantage with flow cells is that they permit the use of alkaline electrolytes for $\mathrm{CO}_{2} \mathrm{RR}^{10}$. It is suggested that alkaline electrolytes can suppress the competing HER, and lower the $\mathrm{CO}_{2} \mathrm{RR}$ activation energy barrier on some $\mathrm{CO}_{2} \mathrm{RR}$ electrocatalysts (e.g., $\mathrm{Cu})^{10}$. In addition, alkaline electrolytes promotes the counter reaction, oxygen evolution reaction (OER), so they can improve the overall energy conversion efficiency in actual $\mathrm{CO}_{2}$ splitting electrolyzers. When our flow cell is tested with $1 \mathrm{M}$ $\mathrm{KOH}$, the $\mathrm{CO}_{2} \mathrm{RR}$ onset potential is reduced to $\sim-0.3 \mathrm{~V}$ (Fig. $3 \mathrm{~b}$ ). It is the most incredible that the current density reaches $288 \mathrm{~mA}$ $\mathrm{cm}^{-2}$ at $-0.61 \mathrm{~V}$, which clearly exceeds the commercialization requirement. The formate selectivity in $1 \mathrm{M} \mathrm{KOH}$ is also satisfactory, and measured to be $97 \%$ at $-0.52 \mathrm{~V}$ and $98 \%$ at $-0.56 \mathrm{~V}$ (Fig. 3c).

Importantly, the durability of our NTD-Bi is not comprised under large current density. It is shown to sustain $\sim 140 \mathrm{~mA} \mathrm{~cm}^{-2}$ at $-0.85 \mathrm{~V}$ in $1 \mathrm{M} \mathrm{KHCO}_{3}$, and $\sim 210 \mathrm{~mA} \mathrm{~cm}^{-2}$ at $-0.58 \mathrm{~V}$ in 1 $\mathrm{M} \mathrm{KOH}$ for $11-13 \mathrm{~h}$ (Fig. 3d). The average formate $\mathrm{FE}$ is calculated to $95-98 \%$. After the $11 \mathrm{~h}$ evaluation in $1 \mathrm{M} \mathrm{KOH}$, the total charge passed is equivalent to the reduction of $\sim 1.0 \mathrm{~L}^{\text {of }} \mathrm{CO}_{2}$ to $\sim 43 \mathrm{mmol}$ of formate. It should be noted that this duration is far from the possible lifetime of our electrocatalyst, but instead limited by our non-optimal flow cell design. The cathode GDL is
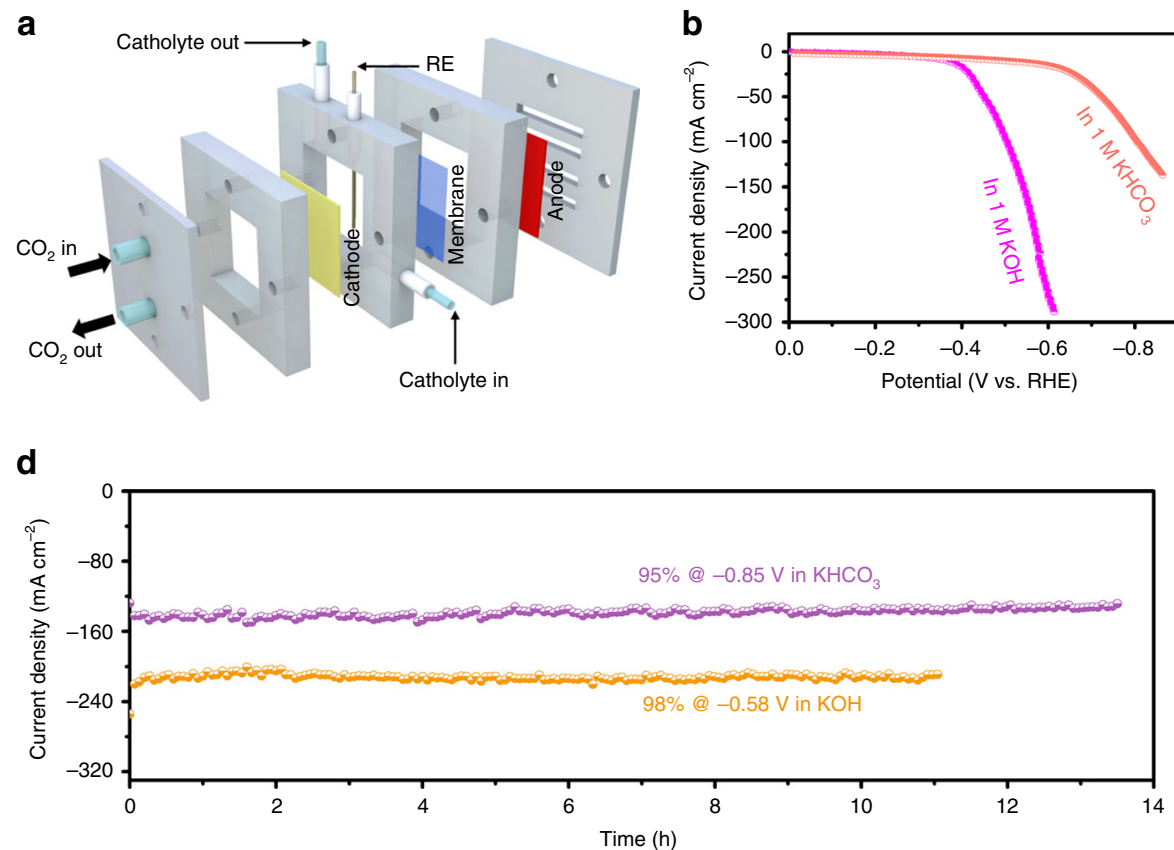
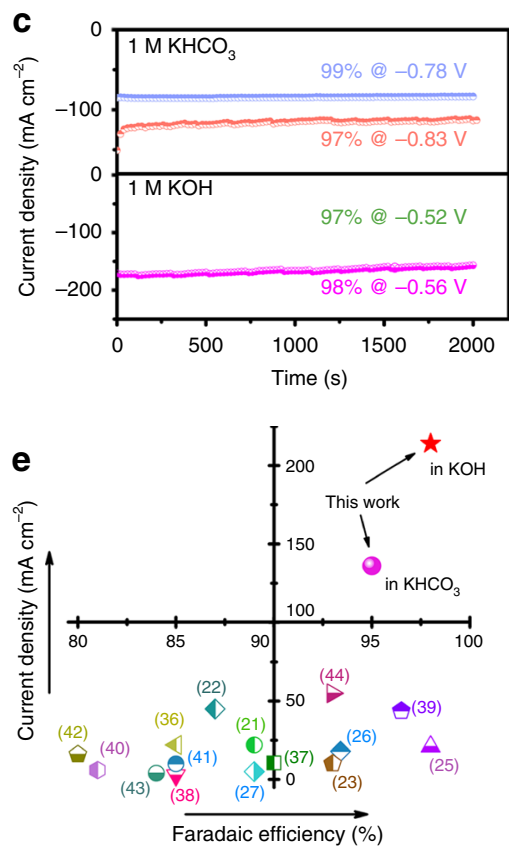

Fig. 3 Electrochemical carbon dioxide reduction measurements in the flow cell. a Schematic illustration of the flow cell configuration. b Polarization curves of nanotube-derived $\mathrm{Bi}\left(\mathrm{NTD}-\mathrm{Bi}\right.$ ) in $1 \mathrm{M} \mathrm{KHCO}_{3}$ or $1 \mathrm{M} \mathrm{KOH}$. $\mathbf{c}$ Chronoamperometric responses at a few different potentials in the two electrolytes. $\mathbf{d}$ Longterm amperometric stability in the two electrolytes. e Comparison of our results with previous data in terms of current density and Faradaic efficiency; corresponding reference numbers are included in brackets 
usually flooded with the electrolyte after continuous operation for $>12 \mathrm{~h}$. We are currently working to alleviate or solve this flooding issue. In Fig. 3e, we compare our measured current density and FE with a few best results from recent formate-producing electrocatalysts. Our NTD-Bi clearly outperforms all of them.

Theoretical simulations. Above electrochemical studies establish the extraordinary activity and selectivity as well as the impressive durability of our NTD-Bi electrochemically converted from $\mathrm{Bi}_{2} \mathrm{O}_{3}$ NTs. We believe that it is owing to the abundant structural defects on surface. In order to gain more insights into the possible impact of defects on the $\mathrm{CO}_{2} \mathrm{RR}$ activity and selectivity, density functional theory (DFT) calculations were carried out to simulate and compare the $\mathrm{CO}_{2} \mathrm{RR}$ pathway on ideal and defective $\mathrm{Bi}$ surfaces (see details in Methods). Since Bi has a layered structure analogous to graphene and black phosphorus, it became very natural for us to focus on its (001) plane as the most representative surface. The (001) plane is the most stable low index plane and natural cleavage plane in Bi single crystals ${ }^{49}$. We built a trilayer model of rhombohedral $\mathrm{Bi}(001)$ in a $3 \times 3$ supercell, and evaluated the influences of the most common types of structural defects, namely 5-7 ring defect, mono-vacancy and di-vacancy. Figure $4 \mathrm{a}$ depicts the optimized adsorption geometry of ${ }^{\star} \mathrm{OCHO}$ (intermediate to formate) on the ideal and defective surfaces. Their energy profiles are summarized in Fig. 4b. In general, Bi is known to significantly stabilize ${ }^{\star} \mathrm{OCHO}$ relative to ${ }^{\star} \mathrm{COOH}$ (intermediate to $\mathrm{CO}$ ) or ${ }^{\star} \mathrm{H}$ (intermediate to $\mathrm{H}_{2}$ ). On the ideal $\mathrm{Bi}$ (001) surface, the formation of ${ }^{\star} \mathrm{OCHO}$ is calculated to have a $\Delta \mathrm{G}$ of $+0.47 \mathrm{eV}$, whereas the $\Delta \mathrm{G}$ for the formation of ${ }^{\star} \mathrm{COOH}$ and ${ }^{\star} \mathrm{H}$ is +1.2 and $+0.97 \mathrm{eV}$, respectively. At the presence of surface 5-7 ring defect or mono-vacancy, $\Delta G$ for the formation of ${ }^{\star} \mathrm{OCHO}$ is lowered to +0.43 or $+0.37 \mathrm{eV}$, respectively (Fig. $4 \mathrm{~b}$ ). Most strikingly, the value is further lowered to $+0.07 \mathrm{eV}$ at the presence of di-vacancy. These results indicate that the presence of structural defects can greatly stabilize ${ }^{\star} \mathrm{OCHO}$. Similar conclusion can be drawn when the simulation is done on other planes (Supplementary Fig. 5). Even though the adsorption of ${ }^{\star} \mathrm{COOH}$ and ${ }^{\star} \mathrm{H}$ is also likewise enhanced on defective Bi surfaces, their formations are still thermodynamically unfavorable compared to ${ }^{\star} \mathrm{OCHO}$ (Supplementary Fig. 6).

As a step further, we simulated the $\mathrm{CO}_{2} \mathrm{RR}$ polarization curves on these surfaces in $\mathrm{CO}_{2}$-saturated $0.5 \mathrm{M} \mathrm{KHCO} 3(\mathrm{pH}=7.2)$ using the mean-field kinetic model ${ }^{50,51}$. The difference is revealed to be strikingly large (Fig. $4 \mathrm{c}$ ). At $-0.6 \mathrm{~V}$, the current density on ideal surface is only $7 \mathrm{~mA} \mathrm{~cm}^{-2}$, while it can be boosted to 17,51 , and $304 \mathrm{~mA} \mathrm{~cm}^{-2}$ in the presence of 5-7 ring defect, monovacancy and di-vacancy, respectively. Because of the simplified theoretical model used and many approximations made, it is not surprising that the simulated polarization curves do not faithfully reflect the experimental data. However, our study firmly captures the profound positive impact of structural defects on the $\mathrm{CO}_{2} \mathrm{RR}$ activity.

Photoelectrochemical carbon dioxide reduction. Encouraged by the superb $\mathrm{CO}_{2} \mathrm{RR}$ performance of NTD-Bi, we further investigated its potential as the co-catalyst to couple with $\mathrm{Si}$ photocathodes for photoelectrochemical (PEC) $\mathrm{CO}_{2} \mathrm{RR}$, and pursued the solar conversion of $\mathrm{CO}_{2}$ to formate (Fig. 5a). To achieve this, hierarchical p-type Si nanowire arrays were fabricated and used as the light-absorbing semiconductor (see details in Methods). The nanowire array structure is designed to enhance the light harvesting capability, and improve its interaction with the cocatalyst ${ }^{52-54} \cdot \mathrm{Bi}_{2} \mathrm{O}_{3}$ NTs were then introduced via spin-coating. Figure 5b, $c$ are the SEM images of $\mathrm{Bi}_{2} \mathrm{O}_{3}$ NT-loaded Si nanowire array photocathode. Individual nanowires are $\sim 5 \mu \mathrm{m}$ in length and $\sim 500 \mathrm{~nm}$ in diameter, uniformly distributed over the pyramidally textured substrate. Close examination reveals that their surfaces are decorated with fibrous $\mathrm{Bi}_{2} \mathrm{O}_{3}$ NTs (Fig. 5c). The intimate contact between the semiconductor and the co-catalyst would ensure the rapid transfer of photogenerated electrons across the interface.

PEC $\mathrm{CO}_{2} \mathrm{RR}$ was performed in $\mathrm{CO}_{2}$-saturated $0.5 \mathrm{M} \mathrm{KHCO}_{3}$ under the illumination of $50 \mathrm{~mW} \mathrm{~cm}^{-2} \mathrm{AM} 1.5 \mathrm{G}$ solar simulator (0.5 sun). Bare $\mathrm{Si}$ photocathode produces exclusively $\mathrm{H}_{2}$
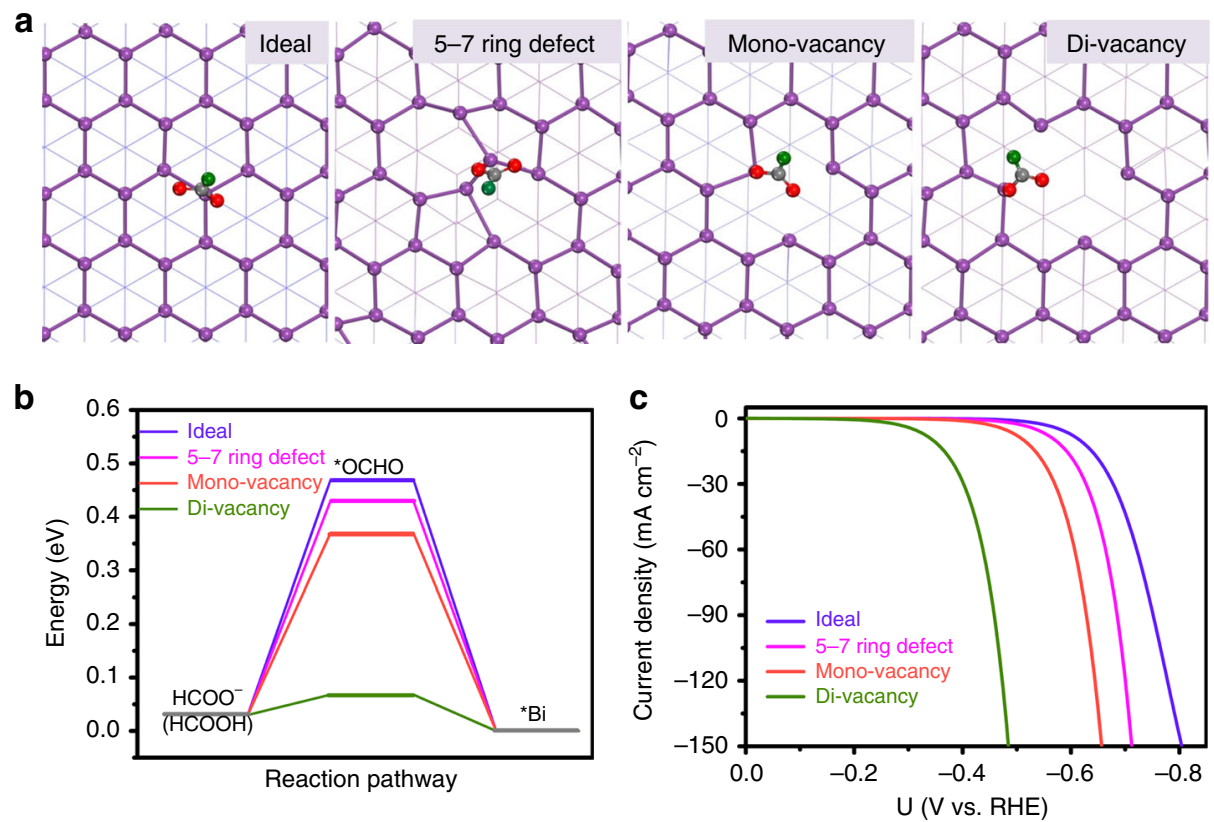

Fig. 4 Theoretical calculations of reaction pathway on ideal and defective $\mathrm{Bi}(001)$ surfaces. a Optimized geometric structures of ${ }^{\star} \mathrm{OCHO}$ adsorbed on ideal and three defective $\mathrm{Bi}(001)$ surfaces as indicated; the pink, gray, red, and green spheres represent $\mathrm{Bi}, \mathrm{C}, \mathrm{O}$, and $\mathrm{H}$ atoms, respectively. b Free-energy profiles for formate production on ideal and defective surfaces. c Corresponding simulated $\mathrm{CO}_{2} \mathrm{RR}$ polarization curves 

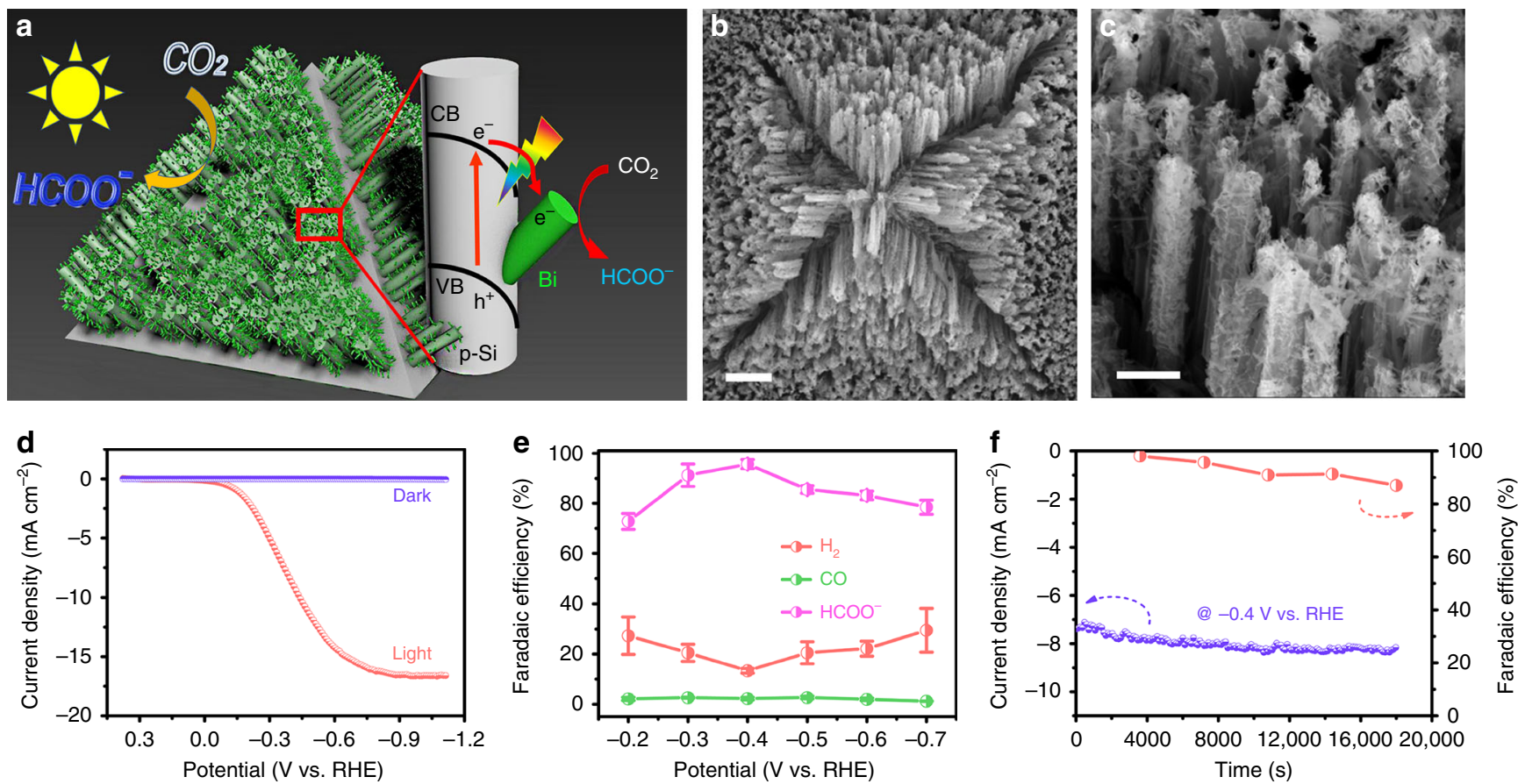

Fig. 5 Photoelectrochemical carbon dioxide reduction on $\mathrm{Si} / \mathrm{Bi}$ photocathode. a Schematic illustration of the structure of the $\mathrm{Si} / \mathrm{Bi}$ photocathode and its working mechanism for PEC $\mathrm{CO}_{2}$ RR. b, c SEM images of $\mathrm{Bi}_{2} \mathrm{O}_{3}$ nanotube (NT)-loaded Si nanowire array photocathode. $\mathbf{d}$ Polarization curves of Si/Bi under dark or 0.5 sun illumination. e Potential-dependent Faradic efficiencies for $\mathrm{HCOO}^{-}, \mathrm{CO}$, and $\mathrm{H}_{2}$ from PEC. $\mathbf{f}$ Change of total current density and formate Faradaic efficiency at $-0.4 \mathrm{~V}$ with time. Scale bar, $5 \mu \mathrm{m}(\mathbf{b}) ; 1 \mu \mathrm{m}$ (c)

(Supplementary Fig. 7). The introduction of co-catalyst markedly improves the PEC activity and shifts the selectivity. Since $\mathrm{Bi}_{2} \mathrm{O}_{3}$ NTs are cathodically converted to NTD-Bi prior to PEC $\mathrm{CO}_{2} \mathrm{RR}$, the actual working co-catalyst is NTD-Bi. The photocathode is named as $\mathrm{Si} / \mathrm{Bi}$ for the sake of clarity. No current is detected under dark (Fig. 5d). Its light polarization curve exhibits an onset potential at $\sim 0 \mathrm{~V}$, and a saturation photocurrent density of $\sim 17 \mathrm{~mA} \mathrm{~cm}^{-2}$. The large saturation photocurrent density (close to the ideal value for $\mathrm{Si}$ photoelectrodes) suggests the full utilization of photogenerated electrons ${ }^{55-58}$. Product analysis discloses that the formate $\mathrm{FE}$ is maintained over $75 \%$ between approximately -0.7 and $-0.3 \mathrm{~V}$, and reaches the peak value of $96 \%$ at $-0.4 \mathrm{~V}$ (Fig. 5e). A small amount of $\mathrm{H}_{2}$ and $\mathrm{CO}$ are detected as the side products. At last, the operation stability of $\mathrm{Si} /$ Bi was evaluated at $-0.4 \mathrm{~V}$ for $5 \mathrm{~h}$. The photocurrent density is maintained around $8 \mathrm{~mA} \mathrm{~cm}^{-2}$, and the corresponding formate FE only experiences a slight decrease to $\sim 90 \%$ at the end of the evaluation (Fig. 5f). As far as we are aware, our photocathode demonstrates the most competitive PEC $\mathrm{CO}_{2} \mathrm{RR}$ performance in literature for formate production with balanced activity, selectivity and stability ${ }^{59-62}$.

\section{Discussion}

In this study, we demonstrated that the $\mathrm{CO}_{2} \mathrm{RR}$ activity and selectivity of Bi were dramatically boosted by introducing surface defects. $\mathrm{Bi}_{2} \mathrm{O}_{3}$ NTs were first synthesized as the template via a facile solution method. They were featured with the unique double-walled tubular structure and highly fragmented outer surface. Under the cathodic polarization, $\mathrm{Bi}_{2} \mathrm{O}_{3}$ NTs were converted to $\mathrm{Bi}$, while the tubular nanostructure was inherited. When tested using a standard $\mathrm{H}$-type electrochemical cell, the converted electrocatalyst enabled $\mathrm{CO}_{2}$ reduction to formate with excellent selectivity (close to $100 \%$ over a broad potential window), great formate partial current density $\left(60 \mathrm{~mA} \mathrm{~cm}^{-2}\right.$ at $\left.-1.05 \mathrm{~V}\right)$, and impressive long-term stability ( $>48 \mathrm{~h}$ ) in $0.5 \mathrm{M} \mathrm{KHCO}_{3}$, which were superior to all previous formate-producing electrocatalysts. When further tested on GDL using a flow cell reactor, NTD-Bi delivered even greater current density of $136 \mathrm{~mA} \mathrm{~cm}^{-2}$ at $-0.86 \mathrm{~V}$ in $1 \mathrm{M} \mathrm{KHCO}_{3}$, and $288 \mathrm{~mA} \mathrm{~cm}^{-2}$ at $-0.61 \mathrm{~V}$ in $1 \mathrm{M}$ $\mathrm{KOH}$, exceeding that of the commercialization requirement. Operando XAS measurements showed that NTD-Bi under the working condition contained abundant structural defects. DFT calculations indicated that the excellent activity and selectivity were due to the presence of defective Bi sites that stabilize the ${ }^{*} \mathrm{OCHO}$ intermediate. At last, NTD-Bi was integrated with p-type Si nanowire arrays for high-performance PEC $\mathrm{CO}_{2} \mathrm{RR}$. Our study here unveils the tremendous potential of $\mathrm{Bi}$ in $\mathrm{CO}_{2} \mathrm{RR}$ electrocatalysis, as well as the remarkable impact of structural defects on its catalytic activity. It represents an important step forward to the commercialization of electrochemical $\mathrm{CO}_{2}$ utilization.

\section{Methods}

Preparation of bismuth oxide NTs. Totally, $100 \mathrm{mg}$ of PVP (M.W. $=55,000$ from Sigma-Aldrich) was first dissolved in $10 \mathrm{~mL}$ of ethylene glycol ( $\geq 99 \%$ from J\&K Chemicals) and $0.1 \mathrm{~mL}$ of deionized water in a $50 \mathrm{~mL}$ three-necked flask at room temperature. $75 \mathrm{mg}$ of bismuth acetate ( $99.99 \%$ from J\&K Chemicals) was added to the above solution and formed a dispersion under the assistance of batch sonication for $30 \mathrm{~min}$. Subsequently, the temperature of the reaction dispersion was rapidly raised to $195^{\circ} \mathrm{C}$, and maintained at this temperature for $15 \mathrm{~min}$ under magnetic stirring and $\mathrm{N}_{2}$ protection. The reaction was then quenched by adding $25 \mathrm{~mL}$ of ethanol and $10 \mathrm{~mL}$ of deionized water. Solid product was washed at least three times with absolute ethanol and deionized water, collected by centrifugation, and then lyophilized. Finally, possible organic residues on surface were removed by calcination in air at $300^{\circ} \mathrm{C}$ for $1 \mathrm{~h}$.

Structural characterization. XRD was recorded on a PANalytical X-ray diffractometer. SEM images were taken on a Zeiss Ultra 55 scanning electron microscope operating at $15 \mathrm{kV}$. STEM imaging was conducted on a Nion HERMES-100 microscope under the accelerating voltage of $60 \mathrm{kV}$ with a 
convergence semi-angle of $35 \mathrm{mrad}$. The low voltage setting was chosen to reduce irradiation damage to the sample. The BF and HAADF images were collected simultaneously using the $\mathrm{BF}$ and $\mathrm{ADF}$ detectors, respectively.

Electrochemical measurements. A total of $1 \mathrm{mg}$ of $\mathrm{Bi}_{2} \mathrm{O}_{3} \mathrm{NTs}, 0.5 \mathrm{mg}$ of Ketjenblack carbon, $10 \mu \mathrm{L}$ of $5 \mathrm{wt} \%$ Nafion solution (Sigma-Aldrich) were first dispersed in $125 \mu \mathrm{L}$ of water and $125 \mu \mathrm{L}$ of ethanol under the assistance of ultrasonication for $>30 \mathrm{~min}$. The thus-formed catalyst ink was then dropcast onto a $1 \times 1 \mathrm{~cm}^{2}$ carbon fiber paper (AvCarb P75 from Fuel Cell Store) to achieve an areal loading of $1 \mathrm{mg} \mathrm{cm}^{-2}$ as the working electrode. Electrochemical measurements were carried out in an H-type two-compartment electrochemical cell. The cathode compartment housed the working electrode and saturated calomel reference electrode (SCE); the anode compartment housed the graphite counter electrode. The two compartments were each filled with $\sim 35 \mathrm{~mL}$ of $0.5 \mathrm{M} \mathrm{KHCO}_{3}$ electrolyte, and separated by a SELEMION anion exchange membrane. The electrolyte was bubbled with ultrapure $\mathrm{CO}_{2}$ gas for $1 \mathrm{~h}$ prior to measurements. The $\mathrm{CO}_{2}$ saturation was maintained during the measurements by continuously bubbling the electrolyte with $\mathrm{CO}_{2}$ at $20 \mathrm{sccm}$. All the potential values were measured against SCE and then converted to RHE. Polarization curves were recorded at $10 \mathrm{mV} \mathrm{s}^{-1}$. Reduction products were qualitatively and quantitatively analyzed using gas chromatography (Tianmei, GC7980) and ion chromatography (Dionex ICS-600) following the method described in our previous publications ${ }^{25,63}$. In brief, for gaseous products $\left(\mathrm{CO}\right.$ or $\mathrm{H}_{2}$ )

$$
\mathrm{FE}_{\text {gas }}(\%)=\frac{Q_{\text {gas }}}{Q_{\text {total }}} \times 100 \%=\frac{\frac{v}{60 \mathrm{~s} / \mathrm{min}} \times \frac{y}{24,000 \mathrm{~cm}^{3} / \mathrm{mol}} \times N \times F}{j} \times 100 \%,
$$

where $v=20 \mathrm{sccm}$ is the $\mathrm{CO}_{2}$ flow rate, $y$ is the measured product concentration in the GC sample loop, $N=2$ is the number of electron transfer to form a molecule of $\mathrm{CO}$ or $\mathrm{H}_{2}, F$ is the Faraday constant $\left(96,500 \mathrm{C} \mathrm{mol}^{-1}\right)$, and $j$ is the total current. For formate in the catholyte

$$
\mathrm{FE}_{\mathrm{HCOO}^{-}}(\%)=\frac{Q_{\mathrm{HCOO}^{-}}}{Q_{\text {total }}} \times 100 \%=\frac{n_{\mathrm{HCOO}^{-}} \times N \times F}{j \times t} \times 100 \%,
$$

where $n_{\mathrm{HCOO}-}$ is the amount of formate determined by the ion chromatography, and $t$ is the electrolysis time.

Operando XAS measurements. Operando XAS including XANES and EXAFS was performed at 5BM-D beamline of APS at Argonne National Laboratory using a home-made in situ XAS cell as described in our previous studies ${ }^{64,65}$. The working electrode was $\mathrm{Bi}_{2} \mathrm{O}_{3}$ NTs-loaded carbon fiber paper. A graphite rod and $\mathrm{Ag} / \mathrm{AgCl}$ electrode were used as the counter electrode and reference electrode, respectively. The electrolyte was $0.5 \mathrm{M} \mathrm{KHCO}_{3} . \mathrm{CO}_{2}$ gas was bubbled constantly at $30 \mathrm{sccm}$ during the measurements to maintain the saturated solution. Bi L fluorescence data were collected by a Vortex ME4 detector using the fluorescence mode. Data reduction and analysis were performed using Athena and Artemis software. For EXAFS fitting, $\mathrm{Bi}$ and $\mathrm{Bi}_{2} \mathrm{O}_{3}$ standards were used to obtain the amplitude reduction factor $\left(\sigma_{0}^{2}\right)$ values, which were further used to calculated other fitting parameters ${ }^{66}$.

Flow cell measurements. Flow cell measurements were performed in a customdesigned flow cell reactor made of polymethyl methacrylate plastic (Supplementary Fig. 4). It consisted of $\mathrm{Bi}_{2} \mathrm{O}_{3}$ NT-loaded GDL $\left(1 \mathrm{mg} \mathrm{cm}^{-2}, 4 \times 4 \mathrm{~cm}^{2}\right)$ as the cathode, a piece of anion exchange membrane (SELEMION, $4 \times 4 \mathrm{~cm}^{2}$ ) as the separator, and a $20 \mathrm{wt} \% \mathrm{Ir} / \mathrm{C}$-loaded GDL $\left(1 \mathrm{mg} \mathrm{cm}^{-2}, 4 \times 4 \mathrm{~cm}^{2}\right)$ as the anode. The cathode and anode compartments were each $\sim 6.5 \mathrm{~cm}^{3}$ in volume. $\mathrm{Ag} / \mathrm{AgCl}$ reference electrode with a diameter of $3.8 \mathrm{~mm}$ was located inside the cathode compartment. During the measurements, $\mathrm{CO}_{2}$ gas was directly fed to the cathode GDL at a rate of $80 \mathrm{sccm}$. The catholyte was $1 \mathrm{M} \mathrm{KHCO}_{3}$ or $1 \mathrm{M} \mathrm{KOH}$. It was forced to continuously circulate through the cathode compartment at a rate of $10 \mathrm{sccm}$.

Fabrication of $\mathrm{Si} / \mathrm{Bi}$ photocathode and PEC measurements. Si nanowire arrays were prepared via the sequential anisotropic etching and isotropic etching of Bdoped p-type Si wafers ((100)-oriented, $500 \mu \mathrm{m}$ thick, $\left.0.2-0.8 \Omega \mathrm{cm}^{2}\right)$ following the method described in literature ${ }^{67}$. The wafer was then cut into small pieces of $1.5 \times$ $1.5 \mathrm{~cm}^{2}$ in size, uniformly spin-coated with $600 \mu \mathrm{L}$ of the alcoholic solution of $\mathrm{Bi}_{2} \mathrm{O}_{3}$ NTs $\left(2 \mathrm{mg} \mathrm{mL}^{-1}\right)$ and Nafion (0.1 wt\%) at $500 \mathrm{rpm}$ for $5 \mathrm{~s}$ and $1500 \mathrm{rpm}$ for $20 \mathrm{~s}$, and dried in air at $40^{\circ} \mathrm{C}$ for $30 \mathrm{~min}$. $\mathrm{PEC} \mathrm{CO}_{2} \mathrm{RR}$ measurements were carried out following the procedure described in our previous publication ${ }^{58}$.

Theoretical calculations. DFT computations were simulated with the Vienna ab initio Simulation Package ${ }^{68}$. The GGA function of the PBE form was used to describe the exchange-correlation energy ${ }^{69}$. After testing the energy cutoff and kpoints convergence, we chose $460 \mathrm{eV}$ as our cutoff energy, and used a $5 \times 5 \times 1 \mathrm{k}$ points grid to sample the unit cell Brillouin zone. We set a $15 \AA$ vacuum space in the z-direction to avoid the periodic influence. The free-energy profiles were calculated by applying the computational electrode model ${ }^{70}$ to efficiently estimate the performance of electrocatalytic reactions. They were expressed as

$$
\Delta G_{\text {ads }}=\Delta E_{\text {ads }}+\Delta E_{\mathrm{ZPE}}-T \Delta S,
$$

where $\Delta G_{\text {ads }}$ was the free energy of the adsorbates, $\Delta E_{\text {ads }}$ was adsorption energy of adsorbates, $\Delta E_{\mathrm{ZPE}}$ and $\Delta S$ were the difference of $E_{\mathrm{ZPE}}$ and $S$, respectively, and $T=$ $298.15 \mathrm{~K}$ was the temperature. $E_{Z P E}$ and $S$ were obtained by vibrational frequencies calculations with harmonic approximation and neglecting contributions from the slab. The contributions of relevant species to free energies are listed in Supplementary Table 2. The micro-kinetic simulations for the $\mathrm{CO}_{2}$ reduction processes were performed based on an established approach ${ }^{50,51}$. The modeling detail is described in Supplementary Note 1.

\section{Data availability}

The data that support the findings of this study are available from the corresponding author upon reasonable request. The source data underlying Figs. la, 2a-h, 3b-d, $4 \mathrm{~b}, \mathrm{c}$, 5d-f and Supplementary Figs. 1d, 2, 3a, 5c, 6a, b, 7a, b are provided as a Source Data file.

Received: 11 April 2019 Accepted: 4 June 2019

Published online: 26 June 2019

\section{References}

1. Chu, S. \& Majumdar, A. Opportunities and challenges for a sustainable energy future. Nature 488, 294-303 (2012).

2. Bushuyev, O. S. et al. What should we make with $\mathrm{CO}_{2}$ and how can we make it? Joule 2, 825-832 (2018).

3. Liu, C., Colón, B. C., Ziesack, M., Silver, P. A. \& Nocera, D. G. Water splitting-biosynthetic system with $\mathrm{CO}_{2}$ reduction efficiencies exceeding photosynthesis. Science 352, 1210-1214 (2016).

4. Schreier, M. et al. Solar conversion of $\mathrm{CO}_{2}$ to $\mathrm{CO}$ using earth-abundant electrocatalysts prepared by atomic layer modification of CuO. Nat. Energy 2 , 17087 (2017).

5. Singh, M. R., Clark, E. L. \& Bell, A. T. Thermodynamic and achievable efficiencies for solar-driven electrochemical reduction of carbon dioxide to transportation fuels. Proc. Natl Acad. Sci. USA 112, E6111-E6118 (2015).

6. Zhu, D. D., Liu, J. L. \& Qiao, S. Z. Recent advances in inorganic heterogeneous electrocatalysts for reduction of carbon dioxide. Adv. Mater. 28, 3423-3452 (2016)

7. Qiao, J. L., Liu, Y. Y., Hong, F. \& Zhang, J. J. A review of catalysts for the electroreduction of carbon dioxide to produce low-carbon fuels. Chem. Soc. Rev. 43, 631-675 (2014).

8. Wu, J. H., Huang, Y., Ye, W. \& Li, Y. G. $\mathrm{CO}_{2}$ reduction: from the electrochemical to photochemical approach. Adv. Sci. 4, 1700194 (2017).

9. Zhou, Y. S. et al. Dopant-induced electron localization drives $\mathrm{CO}_{2}$ reduction to $\mathrm{C}_{2}$ hydrocarbons. Nat. Chem. 10, 974-980 (2018).

10. Dinh, C.-T. et al. $\mathrm{CO}_{2}$ electroreduction to ethylene via hydroxide-mediated copper catalysis at an abrupt interface. Science 360, 783-787 (2018).

11. Zhuang, T.-T. et al. Steering post-C-C coupling selectivity enables high efficiency electroreduction of carbon dioxide to multi-carbon alcohols. Nat. Catal. 1, 421-428 (2018).

12. Jiang, $\mathrm{K}$. et al. Metal ion cycling of $\mathrm{Cu}$ foil for selective $\mathrm{C}-\mathrm{C}$ coupling in electrochemical $\mathrm{CO}_{2}$ reduction. Nat. Catal. 1, 111-119 (2018).

13. Verma, S., Kim, B., Jhong, H. R. M., Ma, S. \& Kenis, P. J. A gross-margin model for defining technoeconomic benchmarks in the electroreduction of $\mathrm{CO}_{2}$. ChemSusChem 9, 1972-1979 (2016).

14. Agarwal, A. S., Zhai, Y., Hill, D. \& Sridhar, N. The electrochemical reduction of carbon dioxide to formate/formic acid: engineering and economic feasibility. ChemSusChem 4, 1301-1310 (2011).

15. Enthaler, S., von Langermann, J. \& Schmidt, T. Carbon dioxide and formic acid-the couple for environmental-friendly hydrogen storage? Energy Environ. Sci. 3, 1207-1217 (2010).

16. Global Roadmap for Implementing $\mathrm{CO}_{2}$ Utilization $\mathrm{CO}_{2}$ Sciences and the Global $\mathrm{CO}_{2}$ Initiative. https://assets.contentful.com/ (2016).

17. Hori, Y., Kikuchi, K. \& Suzuki, S. Production of $\mathrm{CO}$ and $\mathrm{CH}_{4}$ in electrochemical reduction of $\mathrm{CO}_{2}$ at metal electrodes in aqueous hydrogen carbonate solution. Chem. Lett. 14, 1695-1698 (1985).

18. Hori, Y., Wakebe, H., Tsukamoto, T. \& Koga, O. Electrocatalytic process of $\mathrm{CO}$ selectivity in electrochemical reduction of $\mathrm{CO}_{2}$ at metal electrodes in aqueous media. Electrochim. Acta 39, 1833-1839 (1994).

19. Hori, Y. Modern Aspects of Electrochemistry. Vol. 42, 89-189 (Springer, New York, 2008)

20. Chen, Y. \& Kanan, M. W. Tin oxide dependence of the $\mathrm{CO}_{2}$ reduction efficiency on tin electrodes and enhanced activity for tin/tin oxide thin-film catalysts. J. Am. Chem. Soc. 134, 1986-1989 (2012).

21. Lei, F. et al. Metallic tin quantum sheets confined in graphene toward highefficiency carbon dioxide electroreduction. Nat. Commun. 7, 12697 (2016). 
22. Li, F. W., Chen, L., Knowles, G. P., MacFarlane, D. R. \& Zhang, J. Hierarchical mesoporous $\mathrm{SnO}_{2}$ nanosheets on carbon cloth: a robust and flexible electrocatalyst for $\mathrm{CO}_{2}$ reduction with high efficiency and selectivity. Angew. Chem. Int. Ed. 56, 505-509 (2017).

23. Zhang, S., Kang, P. \& Meyer, T. J. Nanostructured tin catalysts for selective electrochemical reduction of carbon dioxide to formate. J. Am. Chem. Soc. 136, 1734-1737 (2014).

24. Yang, H. et al. Selective $\mathrm{CO}_{2}$ reduction on $2 \mathrm{D}$ mesoporous Bi nanosheets. $A d v$. Energy Mater. 8, 1801536 (2018)

25. Han, N. et al. Ultrathin bismuth nanosheets from in situ topotactic transformation for selective electrocatalytic $\mathrm{CO}_{2}$ reduction to formate. Nat. Commun. 9, 1320 (2018)

26. Lee, C. W. et al. Selective electrochemical production of formate from carbon dioxide with bismuth-based catalysts in an aqueous electrolyte. ACS Catal. 8 , 931-937 (2018).

27. Koh, J. H. et al. Facile $\mathrm{CO}_{2}$ electro-reduction to formate via oxygen bidentate intermediate stabilized by high-index planes of Bi dendrite catalyst. ACS Catal. 7, 5071-5077 (2017).

28. Kim, S. et al. Shape-controlled bismuth nanoflakes as highly selective catalysts for electrochemical carbon dioxide reduction to formate. Nano Energy 39, 44-52 (2017).

29. Jia, J. et al. Heterogeneous catalytic hydrogenation of $\mathrm{CO}_{2}$ by metal oxides: defect engineering-perfecting imperfection. Chem. Soc. Rev. 46, 4631-4644 (2017).

30. Yan, D. F. et al. Defect chemistry of nonprecious-metal electrocatalysts for oxygen reactions. Adv. Mater. 29, 1606459 (2017).

31. Chen, Y. H., Li, C. W. \& Kanan, M. W. Aqueous $\mathrm{CO}_{2}$ reduction at very low overpotential on oxide-derived Au nanoparticles. J. Am. Chem. Soc. 134, 19969-19972 (2012).

32. Li, C. W. \& Kanan, M. W. $\mathrm{CO}_{2}$ reduction at low overpotential on $\mathrm{Cu}$ electrodes resulting from the reduction of thick $\mathrm{Cu}_{2} \mathrm{O}$ films. J. Am. Chem. Soc. 134, 7231-7234 (2012).

33. Ma, M., Trześniewski, B. J., Xie, J. \& Smith, W. A. Selective and efficient reduction of carbon dioxide to carbon monoxide on oxide-derived nanostructured silver electrocatalysts. Angew. Chem. Int. Ed. 55, 9748-9752 (2016).

34. Gopalsamy, K. et al. Bismuth oxide nanotubes-graphene fiber-based flexible supercapacitors. Nanoscale 6, 8595-8600 (2014).

35. Li, L., Yang, Y. W., Li, G. H. \& Zhang, L. D. Conversion of a Bi nanowire array to an array of $\mathrm{Bi}-\mathrm{Bi}_{2} \mathrm{O}_{3}$ core-shell nanowires and $\mathrm{Bi}_{2} \mathrm{O}_{3}$ nanotubes. Small 2 , 548-553 (2006).

36. $\mathrm{Li}, \mathrm{Q}$. et al. Tuning $\mathrm{Sn}$-catalysis for electrochemical reduction of $\mathrm{CO}_{2}$ to $\mathrm{CO}$ via the core/shell $\mathrm{Cu} / \mathrm{SnO}_{2}$ structure. J. Am. Chem. Soc. 139, 4290-4293 (2017).

37. Gao, S. et al. Partially oxidized atomic cobalt layers for carbon dioxide electroreduction to liquid fuel. Nature 529, 68-71 (2016)

38. Gao, S. et al. Atomic layer confined vacancies for atomic-level insights into carbon dioxide electroreduction. Nat. Commun. 8, 14503 (2017).

39. Sun, X. F. et al. MoP nanoparticles supported on indium-doped porous carbon: outstanding catalysts for highly efficient $\mathrm{CO}_{2}$ electroreduction. Angew. Chem. Int. Ed. 57, 2427-2431 (2018).

40. Wang, $\mathrm{H}$. et al. Efficient electrocatalytic reduction of $\mathrm{CO}_{2}$ by nitrogen-doped nanoporous carbon/carbon nanotube membranes-a step towards the electrochemical $\mathrm{CO}_{2}$ refinery. Angew. Chem. Int. Ed. 129, 7955-7960 (2017).

41. Zhang, S. et al. Polyethylenimine-enhanced electrocatalytic reduction of $\mathrm{CO}_{2}$ to formate at nitrogen-doped carbon nanomaterials. J. Am. Chem. Soc. 136, 7845-7848 (2014).

42. Luc, W. et al. Ag-Sn bimetallic catalyst with a core-shell structure for $\mathrm{CO}_{2}$ reduction. J. Am. Chem. Soc. 139, 1885-1893 (2017).

43. $\mathrm{Li}, \mathrm{F}$. W. et al. Unlocking the electrocatalytic activity of antimony for $\mathrm{CO}_{2}$ reduction by two-dimensional engineering of the bulk material. Angew. Chem. Int. Ed. 56, 14718-14722 (2017)

44. Zheng, X. L. et al. Sulfur-modulated tin sites enable highly selective electrochemical reduction of $\mathrm{CO}_{2}$ to formate. Joule 1, 794-805 (2017).

45. Mukerjee, S. \& McBreen, J. Hydrogen electrocatalysis by carbon supported Pt and Pt alloys an in situ X-ray absorption study. J. Electrochem. Soc. 143, 2285-2294 (1996).

46. Merte, L. R. et al. Electrochemical oxidation of size-selected Pt nanoparticles studied using in situ high-energy-resolution X-ray absorption spectroscopy. ACS Catal. 2, 2371-2376 (2012).

47. Ramaker, D. E., Mojet, B. L., Oostenbrink, M. T. G., Miller, J. T. \& Koningsberger, D. C. Contribution of shape resonance and Pt-H EXAFS in the $\mathrm{Pt} \mathrm{L}_{2,3} \mathrm{X}$-ray absorption edges of supported Pt particles: application and consequences for catalyst characterization. Phys. Chem. Chem. Phys. 1, 2293-2302 (1999).

48. $\mathrm{Li}$, J. et al. Efficient electrocatalytic $\mathrm{CO}_{2}$ reduction on a three-phase interface. Nat. Catal. 1, 592-600 (2018).
49. Hofmann, P. The surfaces of bismuth: structural and electronic properties Prog. Surf. Sci. 81, 191-245 (2006).

50. Liu, X. Y. et al. Understanding trends in electrochemical carbon dioxide reduction rates. Nat. Commun. 8, 15438 (2017).

51. Hansen, H. A., Varley, J. B., Peterson, A. A. \& Norskov, J. K. Understanding trends in the electrocatalytic activity of metals and enzymes for $\mathrm{CO}_{2}$ reduction to CO. J. Phys. Chem. Lett. 4, 388-392 (2013).

52. Vijselaar, W. et al. Spatial decoupling of light absorption and catalytic activity of Ni-Mo-loaded high-aspect-ratio silicon microwire photocathodes. Nat. Energy 3, 185-192 (2018).

53. Su, Y. D. et al. Single-nanowire photoelectrochemistry. Nat. Nanotechnol. 11, 609-612 (2016).

54. Boettcher, S. W. et al. Energy-conversion properties of vapor-liquidsolid-grown silicon wire-array photocathodes. Science 327, 185-187 (2010).

55. Cabán-Acevedo, M. et al. Efficient hydrogen evolution catalysis using ternary pyrite-type cobalt phosphosulphide. Nat. Mater. 14, 1245-1251 (2015).

56. Chen, F. J. et al. Photoelectroreduction of building-block chemicals. Angew. Chem. Int. Ed. 56, 7181-7185 (2017).

57. $\mathrm{Hu}, \mathrm{S}$. et al. Amorphous $\mathrm{TiO}_{2}$ coatings stabilize $\mathrm{Si}, \mathrm{GaAs}$, and $\mathrm{GaP}$ photoanodes for efficient water oxidation. Science 344, 1005-1009 (2014).

58. $\mathrm{Hu}, \mathrm{Y}$. P. et al. Designing effective $\mathrm{Si} / \mathrm{Ag}$ interface via controlled chemical etching for photoelectrochemical $\mathrm{CO}_{2}$ reduction. J. Mater. Chem. A 6, 21906-21912 (2018)

59. Huang, X., Shen, Q., Liu, J., Yang, N. \& Zhao, G. A $\mathrm{CO}_{2}$ adsorption-enhanced semiconductor/metal-complex hybrid photoelectrocatalytic interface for efficient formate production. Energy Environ. Sci. 9, 3161-3171 (2016).

60. Kang, U. et al. Photosynthesis of formate from $\mathrm{CO}_{2}$ and water at $1 \%$ energy efficiency via copper iron oxide catalysis. Energy Environ. Sci. 8, 2638-2643 (2015).

61. Choi, S. K. et al. Sn-coupled p-Si nanowire arrays for solar formate production from $\mathrm{CO}_{2}$. Adv. Energy Mater. 4, 1301614 (2014).

62. Ding, P. et al. Controlled chemical etching leads to efficient siliconebismuth interface for photoelectrochemical $\mathrm{CO}_{2}$ reduction to formate. Mater. Today Chem. 11, 80-85 (2018)

63. Han, N. et al. Supported cobalt polyphthalocyanine for high-performance electrocatalytic $\mathrm{CO}_{2}$ reduction. Chemistry 3, 652-664 (2017).

64. Weng, Z. et al. Active sites of copper-complex catalytic materials for electrochemical carbon dioxide reduction. Nat. Commun. 9, 415 (2018).

65. Cai, Z. et al. Introducing $\mathrm{Fe}^{2+}$ into nickel-iron layered double hydroxide: local structure modulated water oxidation activity. Angew. Chem. Int. Ed. 57, 9392-9396 (2018).

66. Li, G. G., Bridges, F. \& Booth, C. H. X-ray-absorption fine-structure standards: a comparison of experiment and theory. Phys. Rev. B 52, 6332-6348 (1995).

67. He, L. N., Lai, D., Wang, H. \& Jiang, C. Y. High-efficiency si/polymer hybrid solar cells based on synergistic surface texturing of Si nanowires on pyramids. Small 8, 1664-1668 (2012).

68. Kresse, G. \& Hafner, J. Ab initio molecular-dynamics simulation of the liquidmetal-amorphous-semiconductor transition in germanium. Phys. Rev. B 49, 14251-14269 (1994).

69. Perdew, J. P. \& Wang, Y. Accurate and simple analytic representation of the electron-gas correlation energy. Phys. Rev. B 45, 13244-13249 (1992).

70. Nørskov, J. K. et al. Origin of the overpotential for oxygen reduction at a fuelcell cathode. J. Phys. Chem. B 108, 17886-17892 (2004).

\section{Acknowledgements}

Y.G.L. acknowledges the support from the Ministry of Science and Technology of China (2017YFA0204800), the Priority Academic Program Development of Jiangsu Higher Education Institutions, and Collaborative Innovation Center of Suzhou Nano Science and Technology. Y.F.L. acknowledges the support from the National Natural Science Foundation of China (21873050). W.Z. thanks the financial support from the Ministry of Science and Technology of China (2018YFA0305800) and the National Natural Science Foundation of China (51622211). Z.F. thanks the start-up funding from Oregon State University. Q.F.G. thanks the support from the Postgraduate Research \& Practice Innovation Program of Jiangsu Province (KYCX17_2045). XAS measurements were done at 5-BM-D of DND-CAT at Advanced Photon Source (APS) of Argonne National Laboratory (ANL). DND-CAT is supported through E. I. duPont de Nemours \& Co., Northwestern University, and The Dow Chemical Company. The use of APS of ANL is supported by DOE under Contract Number DE-AC02-06CH11357.

\section{Author contributions}

Y.G.L. conceived the project and designed the experiments. J.L., Z.F., Y.F.L., W.Z. and Y.G.L. supervised the project. Q.G. prepared the material and conducted electrochemical measurements. P.D. carried out PEC measurements. M.X., Y.Z. and W.Z. performed the STEM imaging. X.Z. and Y.F.L. conducted the theoretical calculations. M.W., Q.M. and Z.F. carried out the operando XAS measurements. Q.G., P.D., M.X., X.Z., M.W. and Y.G.L. co-wrote the paper. All authors discussed the results and commented on the paper. 


\section{Additional information}

Supplementary Information accompanies this paper at https://doi.org/10.1038/s41467019-10819-4

Competing interests: The authors declare no competing interests.

Reprints and permission information is available online at http://npg.nature.com/ reprintsandpermissions/

Peer review information: Nature Communications would like to thank the anonymous reviewers for their contribution to the peer review of this work.

Publisher's note: Springer Nature remains neutral with regard to jurisdictional claims in published maps and institutional affiliations. (c) (i) Open Access This article is licensed under a Creative Commons Attribution 4.0 International License, which permits use, sharing, adaptation, distribution and reproduction in any medium or format, as long as you give appropriate credit to the original author(s) and the source, provide a link to the Creative Commons license, and indicate if changes were made. The images or other third party material in this article are included in the article's Creative Commons license, unless indicated otherwise in a credit line to the material. If material is not included in the article's Creative Commons license and your intended use is not permitted by statutory regulation or exceeds the permitted use, you will need to obtain permission directly from the copyright holder. To view a copy of this license, visit http://creativecommons.org/ licenses/by/4.0/.

(C) The Author(s) 2019 